\title{
Prolonged QT Interval: A Tricky Diagnosis?
}

\author{
Martine C. de Bruyne, MD, MSc, Arno W. Hoes, MD, PhD, Jan A. Kors, PhD, \\ Jacqueline M. Dekker, PhD, A. Hofman, MD, PhD, Jan H. van Bemmel, PhD, and \\ Diederick E. Grobbee, MD, PhD
}

Prolonged heart-rate adjusted QT intervals on the electrocardiogram (ECG) are associated with an increased risk for coronary heart disease and sudden death. However, the diagnosis of the prolonged QT interval is hampered by lack of standards. We studied variations in the prevalence of prolonged QT, based on different common definitions, in a large nonhospitalized population, and compared our results with other studies applying the same definitions. The study population consisted of 2,200 men and 3,366 women participants of the Rotterdam Study, $\geq 55$ years old. The QT interval was computed by our Modular ECG Analysis System (MEANS). Three different formulas to adjust QT for heart rate were used: Bazett's formula (QT $)$, a linear regression equation $\left(Q_{\mid r}\right)$, and the QT index (QTI). Prolonged QT occurred frequently in both men and women, and its prevalence increased with age. Women had longer heart-rate adjusted QT intervals than men (mean $\mathrm{QT}_{\mathrm{c}}$

$\mathbf{T}$ he QT interval is of potential use in cardiovascular risk profiling, ${ }^{1-6}$ but the diagnosis of patients with prolonged QT intervals may be hampered by the lack of consensus regarding measurement techniques, ${ }^{7}$ formulas to adjust QT for heart rate, ${ }^{8-11}$ and criteria to define prolonged QT. ${ }^{12}$ Little is known about the influence of these formulas and cut-off criteria on the prevalence of prolonged QT. Furthermore, comparison of the few studies that have been published has been limited by the application of different formulas to adjust QT for heart rate. $6,9,13$ In the present study, we examined the distribution of QT interval length and the prevalence of prolonged QT, heart-rate adjusted, in a large nonhospitalized population of men and women, $\geq 55$ years old. Three different formulas to adjust the QT interval for heart rate were used in order to establish differences between formulas and to compare our findings with published data from other population-based studies.

\section{METHODS}

Study population and data collection: This study is part of the Rotterdam Study, ${ }^{14}$ a population-based

\footnotetext{
From the Department of Epidemiology and Biostatistics, and Department of Medical Informatics, Erasmus University Medical School, Rotterdam; The Institute for Research in Extramural Medicine, Vrije Universiteit, Amsterdam; and Julius Center for Patient-Oriented Research, Utrecht University Academic Hospital, Utrecht, The Netherlands. Manuscript received March 28, 1997; revised manuscript received and accepted July 24, 1997

Address for reprints: Martine de Bruyne, MD, Department of Epidemiology and Biostatistics, Erasmus University Medical School, P.O. Box 1738, 3000 DR Rotterdam, The Netherlands.
}

$433 \mathrm{~ms}$ vs $422 \mathrm{~ms}$ ), and mean values for $\mathrm{QT}_{\mathrm{Ir}}$ were lower than for $\mathrm{QT}_{\mathrm{c}}$ (mean $\mathrm{QT}_{\mathrm{Ir}} 422 \mathrm{~ms}$ in women and $412 \mathrm{~ms}$ in men). Prevalence was highest for prolonged QT $_{\text {Ir }}$ (31\% in men and $26 \%$ in women) and lowest for prolonged QTI (6\% in men and 9\% in women). Comparison with other studies applying the same correction formulas showed large discrepancies in prevalence estimates of prolonged $\mathrm{QT}_{\mathrm{c}}$ and $\mathrm{QT}_{\mathrm{Ir}}$, and to a lesser degree of prolonged QTI, possibly due to differences in measurement techniques. Future research is needed to relate QT interval to prognosis, to obtain measurement technique specific reference values of heart-rate adjusted QT measurements, and to obtain age- and sex-specific threshold values for prolonged QT. Such data are needed to use the QT interval with confidence. (C) 1997 by Excerpta Medica, Inc.

(Am J Cardiol 1997;80:1300-1304)

cohort study aimed at assessing the occurrence and risk factors of chronic diseases in the elderly. Objectives and methods of the Rotterdam Study are described in detail elsewhere. ${ }^{14}$ Briefly, in the Rotterdam Study, all men and women $\geq 55$ years old and living in the Rotterdam district of Ommoord, were invited to participate. Of the 7,129 participants who took part in the study (response rate 69\%), baseline data, collected from 1990 to 1993, included an electrocardiogram (ECG), history of cardiovascular disease, established cardiovascular risk factors, and use of medications. A digitally stored ECG was available for 6,160 participants $(86 \%)$. Fourteen percent of the ECGs were missing due to temporary technical problems with the electrocardiographic recorder. Participants with arrhythmias $(n=290)$ and those with complete left or right bundle branch block $(\mathrm{n}=304)$ were excluded, leaving 2,200 men and 3,366 women in the present study.

QT measurement and correction for heart rate: A 12-lead ECG at rest was recorded with an ESAOTEACTA cardiograph (Florence, Italy) with a sampling frequency of $500 \mathrm{~Hz}$, and stored digitally. All ECGs were processed by the Modular ECG Analysis System (MEANS) ${ }^{15,16}$ to obtain electrocardiographic measurements and diagnostic interpretations. The QT interval was determined over all leads in 1 representative complex, which resulted from selective averaging of dominant beats. ${ }^{15}$ To adjust QT for heart rate, 3 different methods were used. First, we calculated the corrected QT interval ( $\left.\mathrm{QT}_{\mathrm{c}}\right)$ according to Bazett's formula: $\mathrm{QT}_{\mathrm{c}}=\mathrm{QT} / \sqrt{\mathrm{RR}}$, where $\mathrm{RR}$ is the RR 
TABLE I General Characteristics of the Study Population. Values Are Means (With SDs) or Proportions

\begin{tabular}{|lccc|}
\hline & $\begin{array}{c}\text { All } \\
(\mathrm{n}=5,566)\end{array}$ & $\begin{array}{c}\text { Men } \\
(\mathrm{n}=2,200)\end{array}$ & $\begin{array}{c}\text { Women } \\
(\mathrm{n}=3,366)\end{array}$ \\
\hline Age (yrs) & $68.6(8.8)$ & $67.4(8.0)$ & $69.3(9.2)$ \\
Body mass index $\left(\mathrm{kg} / \mathrm{m}^{2}\right)$ & $26.3(3.7)$ & $25.7(3.0)$ & $26.8(4.1)$ \\
Systolic blood pressure $(\mathrm{mm} \mathrm{Hg})$ & $139.0(22.2)$ & $138.5(21.8)$ & $139.3(22.5)$ \\
Diastolic blood pressure $(\mathrm{mm} \mathrm{Hg)}$ & $73.6(11.5)$ & $74.6(11.5)$ & $73.0(11.4)$ \\
Serum total cholesterol $(\mathrm{mmol} / \mathrm{L})$ & $6.7(1.2)$ & $6.3(1.1)$ & $6.9(1.2)$ \\
Serum total potassium (mmol/L) & $4.1(0.3)$ & $4.1(0.3)$ & $4.1(0.3)$ \\
Current cigarette smoking (\%) & 23.3 & 29.5 & 18.9 \\
Systemic hypertension (\%) & 18.4 & 17.1 & 19.3 \\
Antihypertensive medication use (\%) & 30.4 & 27.4 & 32.3 \\
Diabetes mellitus (\%) ${ }^{\dagger}$ & 11.6 & 11.5 & 11.6 \\
History of MI (\%) & 12.5 & 17.8 & 9.1 \\
Left ventricular hypertrophy by ECG (\%) $^{*}$ & 4.7 & 5.6 & 4.1 \\
Negative T-wave (\%) & 7.7 & 8.4 & 7.3 \\
Mean heart rate (beats/min) & $70(12)$ & $68(12)$ & $71(11)$ \\
\hline
\end{tabular}

*Hypertension: systolic blood pressure $>160 \mathrm{~mm} \mathrm{Hg}$ or diastolic blood pressure $>95 \mathrm{~mm} \mathrm{Hg}$.

${ }^{\dagger}$ Diabetes mellitus: nonfasting blood glucose $>11.1 \mathrm{mmol} / \mathrm{L}$ or antidiabetic medication.

${ }^{\ddagger}$ History of $\mathrm{Ml}$ : myocardial infarction by interview or by ECG.

${ }^{\S}$ Negative T-wave: $\geq 1.0 \mathrm{~mm}$ negative deflection in any of leads I to III, $\mathrm{aVL}, \mathrm{aVF}, \mathrm{V}_{2}$ to $\mathrm{V}_{6}$.

\begin{tabular}{|c|c|c|c|c|c|c|}
\hline \multicolumn{7}{|c|}{ Men } \\
\hline Age (yrs) & $\mathrm{n}$ & QT (ms) & $\mathrm{RR}$ (ms) & $\mathrm{QT}_{\mathrm{c}}(\mathrm{ms})^{*}$ & $\mathrm{QT}_{\mathrm{lr}}(\mathrm{ms})^{\dagger}$ & QTI \\
\hline $55-59$ & 434 & 396 & 921 & 415 & 407 & 100.0 \\
\hline $60-64$ & 520 & 397 & 905 & 420 & 410 & 101.1 \\
\hline $65-69$ & 495 & 399 & 896 & 424 & 414 & 102.1 \\
\hline 70-74 & 350 & 399 & 893 & 424 & 414 & 102.3 \\
\hline $75-79$ & 231 & 402 & 894 & 428 & 417 & 103.1 \\
\hline$>80$ & 170 & 400 & 876 & 430 & 417 & 103.4 \\
\hline All & 2,200 & 398 & 901 & 422 & 412 & 101.8 \\
\hline \multicolumn{7}{|c|}{ Women } \\
\hline $55-59$ & 606 & 398 & 868 & 429 & 419 & 102.9 \\
\hline $60-64$ & 678 & 397 & 854 & 431 & 421 & 103.4 \\
\hline $65-69$ & 604 & 399 & 857 & 432 & 422 & 103.7 \\
\hline 70-74 & 566 & 398 & 847 & 434 & 423 & 103.9 \\
\hline $75-79$ & 431 & 400 & 854 & 434 & 423 & 104.1 \\
\hline$>80$ & 481 & 400 & 843 & 437 & 426 & 104.7 \\
\hline All & 3,366 & 398 & 854 & 433 & 422 & 103.7 \\
\hline
\end{tabular}

interval in seconds. ${ }^{17}$ Second, we used a linear regression equation that was also applied in the Framingham Study 9 : $\mathrm{QT}_{\mathrm{lr}}=\mathrm{QT}+\beta^{*}(1-\mathrm{RR})$. Both $\mathrm{QT}_{c}$ and $\mathrm{QT}_{\mathrm{lr}}$ can be interpreted as the QT interval at a heart rate of 60 beats/min. Third, we computed the QT index (QTI) ${ }^{18}$ as used in the Cardiovascular Health Study ${ }^{13}$ : QTI $=$ QT/QT , where $\mathrm{QT}_{\mathrm{p}}$ is the predicted interval and equals: $\mathrm{QT}_{\max } /(1+0.01 *$ heart rate $)$, with $\mathrm{QT}_{\max }=656$ ms. For example, a QTI of 110 denotes a QT interval that is $10 \%$ longer than the predicted QT interval. Based on the literature, 4 definitions of prolonged heart-rate adjusted QT interval were used: $\mathrm{QT}_{\mathrm{c}}>440 \mathrm{~ms}^{6}$ and $460 \mathrm{~ms},{ }^{19} \mathrm{QT}_{1 \mathrm{r}}>420 \mathrm{~ms}$ in men and $>432 \mathrm{~ms}$ in women, ${ }^{9}$ and QTI $>110 .{ }^{13}$
Data analysis: The mean values of QT, RR, $\mathrm{QT}_{\mathrm{c}}, \mathrm{QT}_{\mathrm{lr}}$, and QTI, and the prevalence of prolonged heart-rate adjusted QT, defined in 4 different ways, were assessed in men and women separately and in different age groups. In addition, we studied whether $\mathrm{QT}_{\mathrm{c}}, \mathrm{QT}_{1 \mathrm{r}}$, and QTI were still associated with the RR interval using a linear regression model. In this case, this would indicate that the correction for heart rate with the formula is not complete. Prevalences from published reports were compared with adjusted results from our study, using the same exclusion rules and, if necessary, adjusting for age using linear regression analysis. All analyses were performed for men and women separately, using BMDP statistical software (version 7, 1990, Los Angeles, California).

\section{RESULTS}

The general characteristics of the 2,200 men and 3,366 women are presented in Table I. Women were slightly older, had higher cholesterol levels, smoked less, and had a lower percentage of myocardial infarction than men.

QT interval and heart rate: The relation between QT and RR using linear regression formulas in our study was $\mathrm{QT}_{1 \mathrm{r}}=\mathrm{QT}+$ $0.140 *(1-\mathrm{RR})$ in men and $\mathrm{QT}_{1 \mathrm{r}}=$ $\mathrm{QT}+0.163 *(1-\mathrm{RR})$ in women. In the Framingham Study, application of the linear regression equation had very similar results: $\mathrm{QT}_{\mathrm{lr}}=$ $\mathrm{QT}+0.147 *(1-\mathrm{RR})$ in men and $\mathrm{QT}_{\mathrm{Ir}}=\mathrm{QT}+0.167 *(1-\mathrm{RR})$ in women. ${ }^{9}$ Examination of the linear relation between $\mathrm{QT}_{\mathrm{c}}, \mathrm{QT}_{\mathrm{lr}}$, and QTI with RR showed a negative association of $\mathrm{QT}_{\mathrm{c}}$ (regression coefficient $\mathrm{r}=$ $-0.08, p<0.001)$ and QTI $(r=-0.01, p<0.001)$ with RR. Consequently, $\mathrm{QT}_{\mathrm{c}}$ and QTI do not completely correct QT for heart rate. As expected, there was no significant linear association of $\mathrm{QT}_{1 \mathrm{r}}$ with RR.

Distribution of heart-rate adjusted QT intervals: In Table II, the mean values of QT, RR, QT, $\mathrm{QT}_{1 \mathrm{r}}$, and QTI are presented for different age groups. On average, the unadjusted QT interval was similar in both sexes. Women had shorter RR intervals and consequently longer heart-rate adjusted QT intervals than men. In men, mean $\mathrm{QT}_{c}$ increased from $415 \mathrm{~ms}$ in those age 55 to 59 years to $430 \mathrm{~ms}$ in those $>80$ years. In women, the corresponding values were 429 and 437 


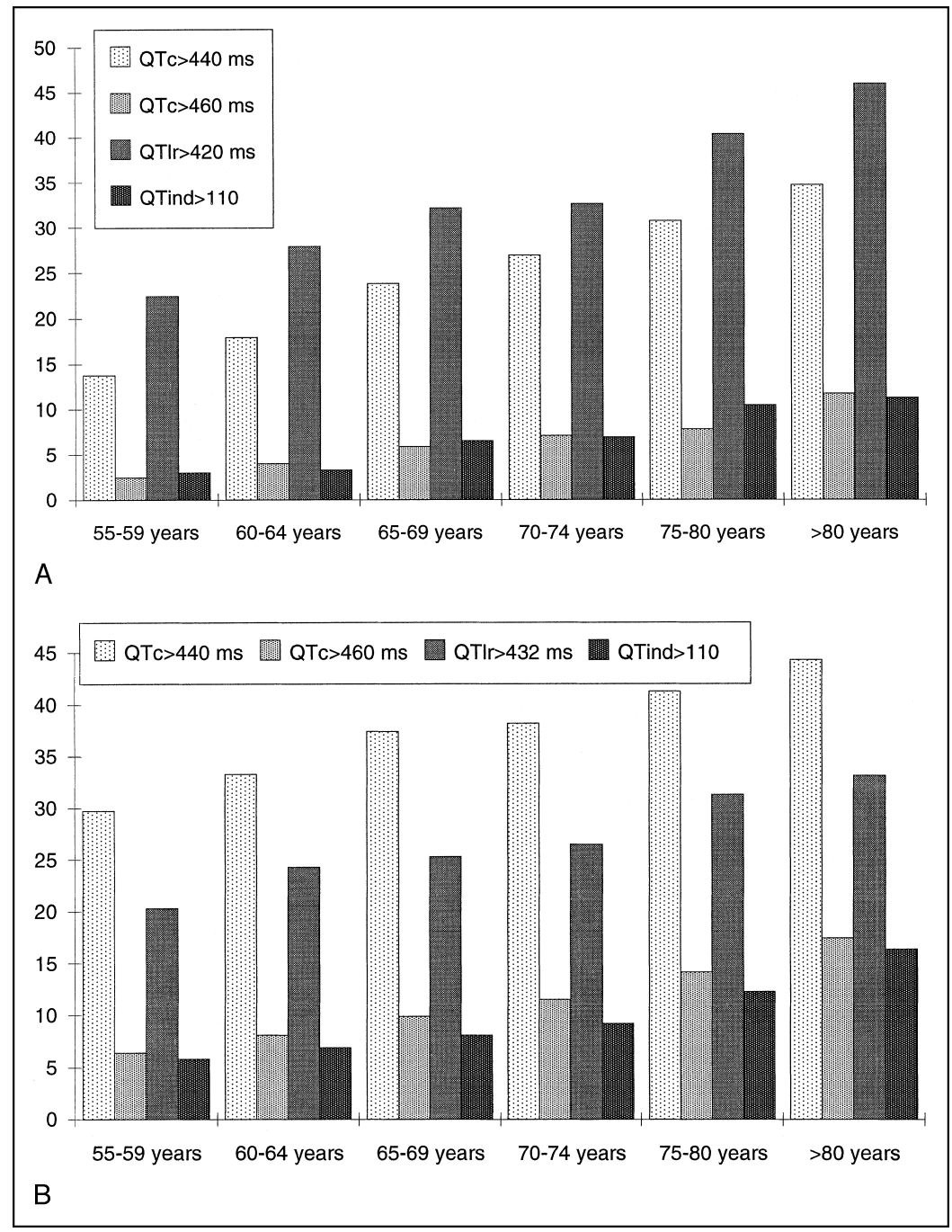

FIGURE 1. A, prevalence of prolonged heart-rate adjusted QT interval in men, using 4 different definitions. $\mathrm{QT}_{\mathrm{c}}=\mathrm{QT} / \sqrt{\mathrm{RR}} ; \mathrm{QT}_{\mathrm{Ir}}=\mathrm{QT}+0.140^{*}(1,000-\mathrm{RR}) ; \mathrm{QTI}=\mathrm{QT} /$

$\left(656 /\left(1+0.01^{*}\right.\right.$ heart rate)). B, prevalence of prolonged heart-rate adjusted QT interval in women, using 4 different definitions. $\mathrm{QT}_{\mathrm{c}}=\mathrm{QT} / \sqrt{ } \mathrm{RR} ; \mathrm{QT}_{\mathrm{Ir}}=\mathrm{QT}+$ $0.163^{*}(1-\mathrm{RR}) ; \mathrm{QTI}=\mathrm{QT} /\left(656 /\left(1+0.01^{*}\right.\right.$ heart rate $\left.)\right)$.

$\mathrm{ms}$, respectively. Overall, $\mathrm{QT}_{\mathrm{c}}$ ranged from 345 to 628 $\mathrm{ms}$ in men and from 329 to $538 \mathrm{~ms}$ in women. In both men and women, mean $\mathrm{QT}_{\mathrm{lr}}$ was about $10 \mathrm{~ms}$ shorter than mean $\mathrm{QT}_{\mathrm{c}}$ in all age groups. Mean QTI increased from 100.0 to 103.4 in men and from 102.9 to 104.7 in women, from the youngest to the oldest age group.

Prevalence of prolonged heart-rate adjusted QT interval: The prevalence of prolonged heart-rate adjusted QT, using the 4 different definitions, is shown in Figure 1. The presence of prolonged $\mathrm{QT}_{c}$, defined as $\mathrm{QT}_{\mathrm{c}}>440 \mathrm{~ms}$ ranged from $13.8 \%$ in men and $29.7 \%$ in women age 55 to 59 , to $34.7 \%$ in men and $44.3 \%$ in women $>80$ years old, and was similar to the prevalence of prolonged $\mathrm{QT}_{\mathrm{lr}}$, but much more prevalent than prolonged QTI intervals. The prevalence of prolonged $\mathrm{QT}_{\mathrm{c}}$, defined as $\mathrm{QT}_{\mathrm{c}}>460 \mathrm{~ms}$, was similar to the prevalence of QTI, ranging from $2.5 \%$ in men and $6.4 \%$ in women ages 55 to 59 , to $11.8 \%$ in men and $17.5 \%$ in women in the oldest age group.
Comparison with other studies: Prevalences reported by 3 other studies and the adjusted prevalence in the Rotterdam Study, applying the same exclusion criteria and adjusting for age, are presented in Table III. Mean $\mathrm{QT}_{\mathrm{c}}$ in men ages 65 to 84 was 411 ms (SD 27) in the Zutphen Study, about $10 \mathrm{~ms}$ shorter than the adjusted mean $\mathrm{QT}_{\mathrm{c}}$ in the Rotterdam Study, ${ }^{14}$ which was $425 \mathrm{~ms}$ (SD 22). Mean $\mathrm{QT}_{\mathrm{lr}}$ was about $375 \mathrm{~ms}$ in men and $388 \mathrm{~ms}$ in women participating in the Framingham Study, ${ }^{9}$ whereas the adjusted mean values of $\mathrm{QT}_{1 \mathrm{r}}$ were 401 $\mathrm{ms}$ (SD 19) in men and $416 \mathrm{~ms}$ (SD 18) in women in the Rotterdam Study. ${ }^{14}$ Prevalences of prolonged $\mathrm{QT}_{\mathrm{c}}$ and prolonged $\mathrm{QT}_{\mathrm{lr}}$ were markedly higher in the Rotterdam Study than in other published studies ${ }^{6,9,13}$ using the same formulas. Prevalence of prolonged QTI was lower in women in the Rotterdam Study compared with women in the Cardiovascular Health Study, ${ }^{13}$ except for the highest age group, but estimates for men were similar.

\section{DISCUSSION}

The results of this study show that a prolonged heart-rate adjusted QT interval is more frequent in women than in men and that the prevalence in both sexes increases markedly with age. Mean values of heart-rate adjusted QT interval and prevalence of prolonged heart-rate adjusted QT vary substantially according to the correction formulas and threshold values used. Comparison of our findings with data presented from other studies showed that even if the same formulas to adjust QT for heart rate are used, large differences in estimates of prevalence of prolonged QT can be observed.

Because $\mathrm{QT}_{\text {lr }}$ was the only formula without a residual linear association with the RR interval, this formula may be preferable to $\mathrm{QT}_{\mathrm{c}}$ and QTI when linear associations of QT with cardiovascular determinants are examined. The linear regression coefficients estimated from the Framingham Study ${ }^{9}$ were very similar to our estimates. Thus, in studies with a relatively small number of participants, regression coefficients need not be derived, but coefficients from the Framingham Study or from the present study can be used.

Comparison with previous studies showed that marked differences in prevalence estimates of prolonged QT were present between studies using the same correction formulas. These discrepancies may at least partly be explained by differences in measure- 


\begin{tabular}{|c|c|c|c|c|}
\hline & $\begin{array}{c}\text { Definition } \\
\text { Prolonged QT }\end{array}$ & $\mathrm{n}$ & $\begin{array}{l}\text { Prevalence } \\
(95 \% \mathrm{Cl})\end{array}$ & $\begin{array}{c}\text { Adj. Prevalence } \\
\text { Rotterdam Study } \\
(95 \% \mathrm{CI})^{\S}\end{array}$ \\
\hline \multicolumn{5}{|l|}{ Zutphen Study 6} \\
\hline & $57.3(54.4-60.2)$ \\
\hline Men, age 29-62 & $\mathrm{QT}_{\mathrm{lr}}>420 \mathrm{~ms}^{\dagger}$ & 2,239 & 2.5 (1.9-3.2) & $14.7(13.1-16.4)$ \\
\hline $\begin{array}{l}\text { Women, age } \\
28-62\end{array}$ & $\mathrm{QT}_{\mathrm{lr}}^{\mathrm{r}}>432 \mathrm{~ms}^{\dagger}$ & 2,779 & $2.5(1.9-3.1)$ & $17.1(15.7-18.5)$ \\
\hline $\begin{array}{l}\text { Cardiovascular } \\
\text { Health Study } 13\end{array}$ & QTI $>110^{\ddagger}$ & & & \\
\hline \multicolumn{5}{|l|}{ Men, } \\
\hline age 65-69 & & 625 & 6.7 (4.9-9.0) & $6.5(4.5-9.0)$ \\
\hline age $70-74$ & & 626 & 10.4) & $-10.0)$ \\
\hline age $75-79$ & & 381 & $12.3(9.2-16.1)$ & $6.8-15.1)$ \\
\hline age $80-84$ & & 201 & $12.4(8.2-17.8)$ & $11.1(5.9-18.6)$ \\
\hline age $>85$ & & 73 & $19.2(10.9-30.1)$ & $11.3(4.7-21.9)$ \\
\hline \multicolumn{5}{|l|}{ Women, } \\
\hline age 65-69 & & 1,097 & $13.4(11.4-15.6)$ & $8.1(6.1-10.6)$ \\
\hline age $70-74$ & & 836 & $16.4(13.9-19.1)$ & $9.2(6.9-11.9)$ \\
\hline age $75-79$ & & 541 & $16.3(13.3-19.6)$ & $12.3(9.3-15.8)$ \\
\hline age $80-84$ & & 229 & $20.1(15.1-25.9)$ & $13.7(9.8-18.5)$ \\
\hline age $>85$ & & 76 & $22.4(13.6-33.4)$ & $19.7(14.7-25.6)$ \\
\hline $\begin{array}{c}{ }^{*} Q T_{c}=Q T / V R R . \\
{ }^{\dagger} Q T_{l r}=Q T+0.140 \\
{ }^{\ddagger} Q T I=Q T / / 656 /(1 \\
{ }^{\S} \text { Adj. prevalence = } \\
\text { ison study and adjustin } \\
\text { Numbers of participa }\end{array}$ & $\begin{array}{l}\text { *(1-RR) in men and } \\
+0.01 \text { *heart rate) }) . \\
\text { djusted prevalence af } \\
\mathrm{g} \text { for age using linear } \\
\text { nts in different age gr }\end{array}$ & $\begin{array}{l}Q T_{\text {Ir }}=Q T \\
\text { ter applyir } \\
\text { regressio }\end{array}$ & $\begin{array}{l}\Gamma+0.163 *(1-R R) \text { in } \\
n g \text { the same exclusion } c \\
n \text { if necessary. }\end{array}$ & $\begin{array}{l}\text { iteria as in the compar } \\
\text { resented in Table II. }\end{array}$ \\
\hline
\end{tabular}

the problem of intra- and interobserver variability among different physicians measuring ECGs, are preferable to manual measurements.

The definition of prolonged heartrate adjusted QT, depending on the threshold value used to distinguish between normal and prolonged QT, can be based on prognostic implications for clinical end points. Depending on the purpose of diagnosing prolonged QT, higher or lower thresholds and associated risk levels may be considered relevant, which also influences the number of subjects detected with prolonged QT. Instead of dichotomous thresholds, multilevel risk groups or continuous estimates associated with heart-rate adjusted QT may be studied. Because women have systematically longer (about $10 \mathrm{~ms}$ ) heart-rate adjusted QT intervals, ${ }^{5,9,20-22}$ it seems that the threshold value for prolonged $\mathrm{QT}_{\mathrm{c}}$ and $\mathrm{QT}_{\mathrm{lr}}$ should be higher in women than in men.

Using data from large populationbased follow-up studies, such as the Rotterdam Study, ${ }^{14}$ may offer an opportunity to circumvent the problem

ment techniques. In the Rotterdam Study, ${ }^{14}$ the QT interval was measured by computer over all leads. The greatest differences were found between the Rotterdam Study and 2 studies ${ }^{6,9}$ using manual measurements. In the Zutphen Study, ${ }^{6}$ electrocardiographic intervals were measured manually with a digitizing tablet, taking the longest QT interval from leads I, II, III, $\mathrm{V}_{2}$ or $\mathrm{V}_{6}$, and in the Framingham Study ${ }^{9}$ measurements were performed manually in all 12 leads. Our findings were more similar to those of the Cardiovascular Health Study ${ }^{13}$ in which a computer program was used in combination with an interactive graphics procedure for correcting computer measurement errors. This computer program applies another method to detect the end of the $\mathrm{T}$ wave than our MEANS program. This is important, in view of the large variability reported between different human observers, different computer programs, and between human observers and computer programs, in measurements of the end of the T wave. ${ }^{7}$ Another explanation for part of the discrepancies in prevalence estimates between populations may be differences in prevalences of cardiovascular risk indicators, such as body mass index, medication use, or coronary heart disease.

Which measurement technique should be preferred to diagnose prolonged QT is unclear. Even though QT intervals have been found to differ systematically, the association of prolonged QT intervals, established with different measurement techniques, with future cardiovascular disease, has been shown in many studies. However, it seems clear that computerized QT measurements using a single program, and excluding of the lack of standards by establishing specific reference values for each electrocardiographic computer program or manual measurement technique separately. For each method, age- and sex-specific normal values of QT interval can be assessed, together with threshold values for the prolonged heart-rate adjusted QT interval. Thresholds should depend on the additional risk associated with a certain length of the heart-rate adjusted QT interval, for example, a two- or threefold risk for cardiovascular morbidity or mortality. This would facilitate uniform diagnoses of those with prolonged heart-rate adjusted QT intervals, and link them to established levels of risk. Consequently, prevalence of prolonged heart-rate adjusted QT can be compared between different populations. More importantly, this would enable physicians to target preventive measures at patients with QT intervals, inferring increased cardiovascular risk. At present, in the absence of these measurement technique specific reference values, the prolonged QT interval remains a tricky diagnosis.

1. Moss AJ, Schwartz PJ, Crampton RS, Tzivoni D, Locati EH, MacCluer J, Hall WJ, Weitkamp L, Vincent GM, Garson AJ. The long QT syndrome. Prospective longitudinal study of 328 families. Circulation 1991;84:1136-1144.

2. Schwartz PJ, Wolf S. QT interval prolongation as predictor of sudden death in patients with myocardial infarction. Circulation 1978;57:1074-1077.

3. Ahnve S. QT interval prolongation in acute myocardial infarction. Eur Heart J 1985;6(suppl D):85-95.

4. Bellavere F, Ferri M, Guarini L, Bax G, Piccoli A, Cardone C, Fedele D. Prolonged QT period in diabetic autonomic neuropathy: a possible role in sudden cardiac death? Br Heart J 1988;59:379-383.

5. Schouten EG, Dekker JM, Meppelink P, Kok FJ, Vandenbroucke JP, Pool J. 
QT interval prolongation predicts cardiovascular mortality in an apparently healthy population. Circulation 1991;84:1516-1523.

6. Dekker JM, Schouten EG, Klootwijk P, Pool J, Kromhout D. Association between QT interval and coronary heart disease in middle-aged and elderly men. The Zutphen Study. Circulation 1994;90:779-785.

7. Willems JL, Arnaud P, van Bemmel JH, Bourdillon PJ, Brohet C, Dalla Volta S, Damgaard Andersen J, Degani R, Denis B, Demeester M, et al. Assessment of the performance of electrocardiographic computer programs with the use of a reference data base. Circulation 1985;71:523-534.

8. Funck-Brentano C, Jaillon P. Rate-corrected QT interval: techniques and limitations. Am J Cardiol 1993;72:17B-22B.

9. Sagie A, Larson MG, Goldberg RJ, Bengtson JR, Levy D. An improved method for adjusting the QT interval for heart rate (the Framingham Heart Study). Am J Cardiol 1992;70:797-801.

10. Rautaharju PM, Zhou SH, Wong S, Prineas R, Berenson GS. Functional characteristics of QT prediction formulas. The concepts of QTmax and QT rate sensitivity. Comput Biomed Res 1993;26:188-204.

1 1. Karjalainen J, Viitasalo M, Manttari M, Manninen V. Relation between QT intervals and heart rates from 40 to 120 beats/min in rest electrocardiograms of men and a simple method to adjust QT interval values. J Am Coll Cardio 1994;23:1547-1553

12. Moss AJ. Measurement of the QT interval and the risk associated with QTc interval prolongation: a review. Am J Cardiol 1993;72:23B-25B.

13. Rautaharju PM, Manolio TA, Psaty BM, Borhani NO, Furberg CD. Correlates of QT prolongation in older adults (the Cardiovascular Health Study) Cardiovascular Health Study Collaborative Research Group. Am J Cardiol 1994; 73:999-1002.

14. Hofman A, Grobbee DE, De Jong PTVM, Van den Ouweland FA. Determi- nants of disease and disability in the elderly: the Rotterdam Elderly Study. Eur J Epidemiol 1991;7:403-422.

15. Van Bemmel JH, Kors JA, Van Herpen G. Methodology of the modular ECG analysis system MEANS. Methods Inf Med 1990;29:346-353.

16. Willems JL, Abreu LC, Arnaud P, Van Bemmel JH, Brohet C, Degani R, Denis B, Gehring J, Graham I, Van Herpen G. The diagnostic performance of computer programs for the interpretation of electrocardiograms. $N$ Engl J Med 1991;325:1767-1773

17. Bazett HC. An analysis of time relations of the electrocardiogram. Heart 1920;7:353-370.

18. Rautaharju PM, Warren JW, Calhoun HP. Estimation of QT prolongation. A persistent, avoidable error in computer electrocardiography. J Electrocardiol 1990;23:111-117.

19. Schwartz PJ, Locati EH, Moss AJ, Crampton RS, Trazzi R, Ruberti U. Left cardiac sympathetic denervation in the therapy of congenital long QT syndrome. A worldwide report. Circulation 1991;84:503-511.

20. Rautaharju PM, Zhou SH, Wong S, Calhoun HP, Berenson GS, Prineas R, Davignon A. Sex differences in the evolution of the electrocardiographic QT interval with age. Can J Cardiol 1992;8:690-695.

21. Lehmann MH, Timothy KW, Frankovich D, Fromm BS, Keating M, Locati EH, Taggart RT, Towbin JA, Moss AJ, Schwartz PJ, Vincent GM. Age-gender influence on the rate-corrected QT interval and the QT-heart rate relation in families with genotypically characterized long QT syndrome. J Am Coll Cardiol 1997;29:93-99.

22. Burke JH, Ehlert FA, Kruse JT, Parker MA, Goldberger JJ, Kadish AH. Gender-specific differences in the QT interval and the effect of autonomic tone and menstrual cycle in healthy adults. Am J Cardiol 1997;79: $178-181$. 